\title{
AgRP Neurons Can Increase Food Intake during Conditions of Appetite Suppression and Inhibit Anorexigenic Parabrachial Neurons
}

\author{
Rachel A. Essner, ${ }^{\star}$ Alison G. Smith, ${ }^{\star}$ Adam A. Jamnik, Anna R. Ryba, ${ }^{-Z o e ~ D . ~ T r u t n e r, ~ a n d ~ M a t t h e w ~ E . ~ C a r t e r ~}$ \\ Department of Biology, Program in Neuroscience, Williams College, Williamstown, Massachusetts 01267
}

To maintain energy homeostasis, orexigenic (appetite-inducing) and anorexigenic (appetite suppressing) brain systems functionally interact to regulate food intake. Within the hypothalamus, neurons that express agouti-related protein (AgRP) sense orexigenic factors and orchestrate an increase in food-seeking behavior. In contrast, calcitonin gene-related peptide (CGRP)-expressing neurons in the parabrachial nucleus (PBN) suppress feeding. PBN CGRP neurons become active in response to anorexigenic hormones released following a meal, including amylin, secreted by the pancreas, and cholecystokinin (CCK), secreted by the small intestine. Additionally, exogenous compounds, such as lithium chloride ( $\mathrm{LiCl}$ ), a salt that creates gastric discomfort, and lipopolysaccharide (LPS), a bacterial cell wall component that induces inflammation, exert appetite-suppressing effects and activate PBN CGRP neurons. The effects of increasing the homeostatic drive to eat on feeding behavior during appetite suppressing conditions are unknown. Here, we show in mice that food deprivation or optogenetic activation of AgRP neurons induces feeding to overcome the appetite suppressing effects of amylin, CCK, and LiCl, but not LPS. AgRP neuron photostimulation can also increase feeding during chemogenetic-mediated stimulation of PBN CGRP neurons. AgRP neuron stimulation reduces Fos expression in PBN CGRP neurons across all conditions. Finally, stimulation of projections from AgRP neurons to the PBN increases feeding following administration of amylin, CCK, and LiCl, but not LPS. These results demonstrate that AgRP neurons are sufficient to increase feeding during noninflammatory-based appetite suppression and to decrease activity in anorexigenic PBN CGRP neurons, thereby increasing food intake during homeostatic need.

Key words: AgRP; appetite; CGRP; ChR2; food intake; parabrachial nucleus

Significance Statement

The motivation to eat depends on the relative balance of activity in distinct brain regions that induce or suppress appetite. An abnormal amount of activity in neurons that induce appetite can cause obesity, whereas an abnormal amount of activity in neurons that suppress appetite can cause malnutrition and a severe reduction in body weight. The purpose of this study was to determine whether a population of neurons known to induce appetite ("AgRP neurons") could induce food intake to overcome appetite-suppression following administration of various appetite-suppressing compounds. We found that stimulating AgRP neurons could overcome various forms of appetite suppression and decrease neural activity in a separate population of appetitesuppressing neurons, providing new insights into how the brain regulates food intake.

\section{Introduction}

The motivation to eat depends on the relative balance of activity between orexigenic and anorexigenic brain systems (Sternson and

Received March 23, 2017; revised July 11, 2017; accepted Aug. 1, 2017.

Author contributions: R.A.E., A.G.S., and M.E.C. designed research; R.A.E., A.G.S., A.A.J., A.R.R., Z.D.T., and M.E.C. performed research; R.A.E., A.G.S., and M.E.C. analyzed data; R.A.E., A.G.S., A.A.J., A.R.R., Z.D.T., and M.E.C. wrote the paper.

This work was supported by National Institutes of Health Grant DK105510 from the National Institute of Digestive and Diabetes and Kidney Diseases (NIDDK) to M.E.C. We thank R. Palmiter for the Calca ${ }^{\text {Cre }}$ mice, and N. Goldstein, B. Levine, and C. Mook for constructive comments and feedback on the paper.

${ }^{*}$ R.A.E. and A.G.S. contributed equally to this work.

The authors declare no competing financial interests.
Eiselt, 2017). Agouti-related protein (AgRP)-expressing neurons in the arcuate nucleus of the hypothalamus are a key orexigenic neuronal population that increases food intake behavior in response to homeostatic need (Ilnytska and Argyropoulos, 2008; Sternson, 2013). These neurons also express neuropeptide $\mathrm{Y}$ and the inhibitory neurotransmitter GABA (Tong et al., 2008; Wu et al., 2009). AgRP neurons increase activity in response to food deprivation and administration of the orexigenic hormone ghre-

Correspondence should be addressed to Dr. Matthew E. Carter, Department of Biology, Thompson Biology Lab Room 218, Williams College, Williamstown, MA 01267. E-mail: mc10@williams.edu.

D0I:10.1523/JNEUROSCI.0798-17.2017

Copyright $\odot 2017$ the authors $\quad 0270-6474 / 17 / 378678-10 \$ 15.00 / 0$ 
lin, as demonstrated by Fos expression (an indirect marker of neuronal activity), electrophysiological recording in brain slices, and in vivo calcium imaging (Takahashi and Cone, 2005; Betley et al., 2015; Chen et al., 2015; Mandelblat-Cerf et al., 2015). Furthermore, AgRP neurons are both necessary and sufficient for mediating feeding behavior: chemogenetic inhibition of AgRP neurons significantly decreases feeding (Krashes et al., 2011) and genetic ablation of AgRP neurons causes starvation (Luquet et al., 2005); in contrast, optogenetic or chemogenetic stimulation of AgRP neurons causes a rapid and reversible increase in food intake (Aponte et al., 2011; Krashes et al., 2011).

To orchestrate food intake behavior, AgRP neurons project to multiple, redundant downstream neuronal populations (Betley et al., 2013). To maximally promote food intake, AgRP neurons may simultaneously inhibit other brain systems that actively suppress appetite. For example, stimulation of AgRP neurons can inhibit anorexigenic neurons in the paraventricular thalamic nucleus, indirectly restoring hunger-like response patterns in insular cortex following a meal (Livneh et al., 2017).

AgRP neurons may also directly or indirectly inhibit anorexigenic neurons in the parabrachial nucleus (PBN) that express calcitonin gene-related peptide (CGRP) and have been shown to suppress appetite (Carter et al., 2013). These neurons increase activity in response to anorexigenic signals such as amylin and cholecystokinin (CCK), hormones secreted following a meal by the pancreas and small intestine, respectively (Becskei et al., 2007; Carter et al., 2013). PBN CGRP neurons also increase Fos expression following administration of exogenous appetite suppressants such as lithium chloride ( $\mathrm{LiCl})$, a salt that creates gastric discomfort, and lipopolysaccharide (LPS), a bacterial cell wall component that induces inflammation (Rinaman and Dzmura, 2007; Carter et al., 2013, 2015). Optogenetic or chemogenetic stimulation of PBN CGRP neurons rapidly and reversibly reduces food intake (Carter et al., 2013; Campos et al., 2016). During baseline conditions, chemogenetic inactivation of PBN CGRP neurons increases meal size and duration but has no effect on total food intake over time (Campos et al., 2016). In contrast, during appetite-suppressing conditions, chemogenetic inactivation of PBN CGRP neurons increases total food intake (Carter et al., 2013; Campos et al., 2016). Permanent inactivation of PBN CGRP neurons via tetanus-toxin completely eliminates the satiating effects of CCK (Campos et al., 2016).

AgRP neurons send GABAergic projections to the PBN (Wu et al., 2009; Atasoy et al., 2012; Betley et al., 2013; Campos et al., 2016), suggesting that AgRP neurons may directly or indirectly inhibit PBN CGRP neurons. Consistent with this hypothesis, CGRP neurons are highly active following AgRP neuron ablation (Wu et al., 2009; Campos et al., 2016), and stimulation of AgRPto-PBN projections reduces expression of Fos in PBN CGRP neurons following administration of the anorexigenic hormone exendin-4 (Campos et al., 2016).

We tested the hypotheses that AgRP neurons could overcome appetite suppression following administration of anorexigenic compounds and decrease activity in PBN CGRP neurons. We found that stimulation of AgRP neurons or AgRP neuron-to-PBN projections increased food intake following administration of amylin, CCK, and LiCl, but not LPS. Stimulation of AgRP neurons ameliorated appetite suppression caused by chemogenetic stimulation of PBN CGRP neurons, and reduced Fos expression in PBN CGRP neurons across all conditions. Our findings show that AgRP neurons can overcome noninflammatory based appetite suppression and decrease activity in anorexigenic PBN CGRP neurons, elucidating how the brain balances orexigenic and anorexigenic inputs to regulate feeding behavior.

\section{Materials and Methods}

Mice. All experiments were approved by the Institutional Animal Care and Use Committee at Williams College and were performed in accordance with the guidelines described in the National Institutes of Health Guide for the Care and Use of Laboratory Animals. We used male AgRPCre/+ mice (Tong et al., 2008; Jackson Laboratories, Catalog \#012899) bred on a C57BL/6 background. In some experiments, we crossed $\mathrm{AgRP} P^{\mathrm{Cre} / \mathrm{Cre}}$ mice with $\mathrm{Calca}^{\mathrm{Cre} /+}$ mice (Carter et al., 2013) to produce $\mathrm{AgRP} \mathrm{Cre} /+^{\text {; }}$ $\mathrm{Calca}^{\mathrm{Cre} /+}$ mice. All mice were 7-9 weeks old at the time of surgery and no more than $16-20$ weeks old at the cessation of experiments. Mice were housed in individual cages with a $12 \mathrm{~h} \mathrm{light/dark} \mathrm{cycle} \mathrm{at} 22^{\circ} \mathrm{C}$.

Virus preparation. Cre-inducible recombinant adeno-associated virus serotype 1 (AAV1) vectors carrying either ChR2-mCherry (AV-1-20297P), eGFP (AV-1-ALL854), or TdTomato (AV-1-ALL864) transgenes were obtained from the Vector Core of the University of Pennsylvania. Creinducible AAV8 vectors containing either $\mathrm{hM}_{3}$ Dq-mCherry (44361) or mCherry (50459) were obtained from Addgene. Viral aliquots were stored at $-80^{\circ} \mathrm{C}$ before stereotaxic injection.

Stereotaxic surgery. Mice were anesthetized with $4 \%$ isoflurane and placed on a stereotaxic frame (David Kopf Instruments). Once on the frame and throughout the remainder of surgical procedures, mice received $1-2 \%$ isoflurane trans-nasally. After the skull was exposed and leveled in the horizontal plane, AAV was stereotaxically injected unilaterally or bilaterally, as described in the text, into the arcuate nucleus [Fig. $1 A$ anteroposterior (AP), $-1.4 \mathrm{~mm}$; mediolateral (ML), $0.45 \mathrm{~mm}$; dorsoventral (DV), $-5.9 \mathrm{~mm}$ ]. In some experiments, AAV was also stereotaxically injected into the parabrachial nucleus (AP, $-4.9 \mathrm{~mm}$; ML, $1.4 \mathrm{~mm}$; $\mathrm{DV}, 3.8 \mathrm{~mm}$ ). A total of $0.5 \mu \mathrm{l}$ of virus was injected at a rate of $0.1 \mu \mathrm{l} / \mathrm{min}$ and was allowed $8-10 \mathrm{~min}$ to diffuse before the injection needle was removed.

After viral injection, mice received unilateral surgical implantation of a mono fiber-optic cannula (Doric Lenses) above the arcuate nucleus (Fig. 1A; AP, $-1.4 \mathrm{~mm}$; ML, $0.45 \mathrm{~mm}$; DV $5.5 \mathrm{~mm}$ ). In subsequent experiments, mice received unilateral or bilateral surgical implantation of fiber-optic cannulae above the PBN (AP, $-5.2 \mathrm{~mm}$; ML, $1.6 \mathrm{~mm}$; DV, $3.0 \mathrm{~mm}$ ). The cannulae were fixed onto the skull with $\mathrm{C} \& \mathrm{~B}$ Metabond (Parkell) and dental acrylic. All mice were provided at least $14 \mathrm{~d}$ to recover from surgery before the start of experimental procedures. Following behavioral experiments, brain sections containing the arcuate nucleus were inspected for expression of virus and proper implantation of fiber-optic cannulae (Fig. 1B,C); animals that did not show viral expression (mCherry or GFP fluorescence) or proper cannulae placement were not included in subsequent data analysis.

Food intake measurements. For feeding assays, mice were individually housed in food/liquid intake measurement cages attached to water bottles mounted on scales (Omnitech Electronics). Mice were provided with a liquid diet of Vanilla Ensure (Abbott Nutrition) diluted in a 1:2 ratio with water. This liquid diet had a caloric density of $450 \mathrm{kcal} / \mathrm{L}$. Mice were allowed to habituate for a minimum of $72 \mathrm{~h}$. Bottles containing liquid diet were washed and disinfected daily and fully replenished at the beginning of the light cycle. Because the mice tended to increase their food intake in response to the replenishment of the liquid diet, food intake trials were performed at least $3 \mathrm{~h}$ after exchanging fresh food bottles. All food intake measurements were obtained during the middle $4 \mathrm{~h}$ of the inactive cycle (4-7 $\mathrm{h}$ after light onset).

Photostimulation. Mice were attached to fiber-optic cables ( $1.5 \mathrm{~m}$ long, $200 \mu \mathrm{m}$ diameter; Doric Lenses) coated with opaque heat-shrink tubing and allowed to acclimate for at least $5 \mathrm{~d}$ before experimental sessions. Photostimulation was produced by a $473 \mathrm{~nm}$ blue-light laser (LaserGlow) driven by a Master-8 Pulse Stimulator (AMPI), which was programmed to deliver $10 \mathrm{~ms}$ light pulses at $20 \mathrm{~Hz}$ for $1 \mathrm{~s}$ every $4 \mathrm{~s}$ for $20 \mathrm{~min}$ (Fig. 1D). For each trial, food intake was recorded for exactly $1 \mathrm{~h}$ : the 20 min before, during, and after photostimulation (Fig. 1D).

Pharmacology. All anorexigenic compounds were prepared in $0.9 \%$ sterile saline and stored at $-20^{\circ} \mathrm{C}$ before use. For each food intake trial, $250 \mu \mathrm{l}$ of $0.9 \%$ sterile saline, amylin $(10 \mu \mathrm{g} / \mathrm{kg}$; Bachem $)$, CCK $(10 \mu \mathrm{g} / \mathrm{kg}$; Bachem), LiCl ( $84 \mathrm{mg} / \mathrm{kg}$; Bachem), or LPS (50 $\mu \mathrm{g} / \mathrm{kg}$; Calbiochem), was administered intraperitoneally. For the quick acting compounds 
A

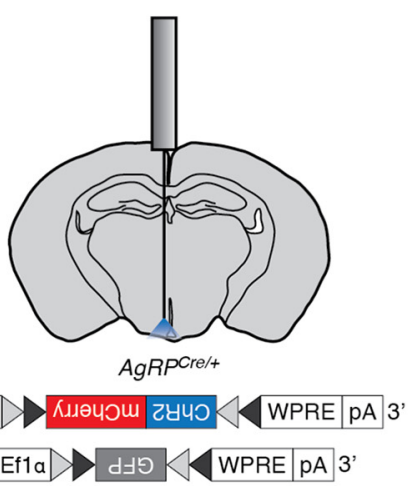

D

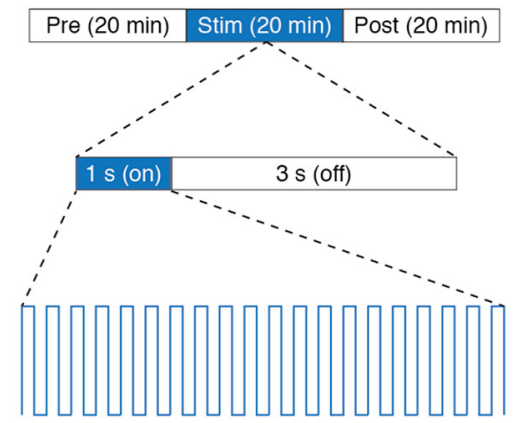

$20 \mathrm{~Hz}, 473 \mathrm{~nm}$

E
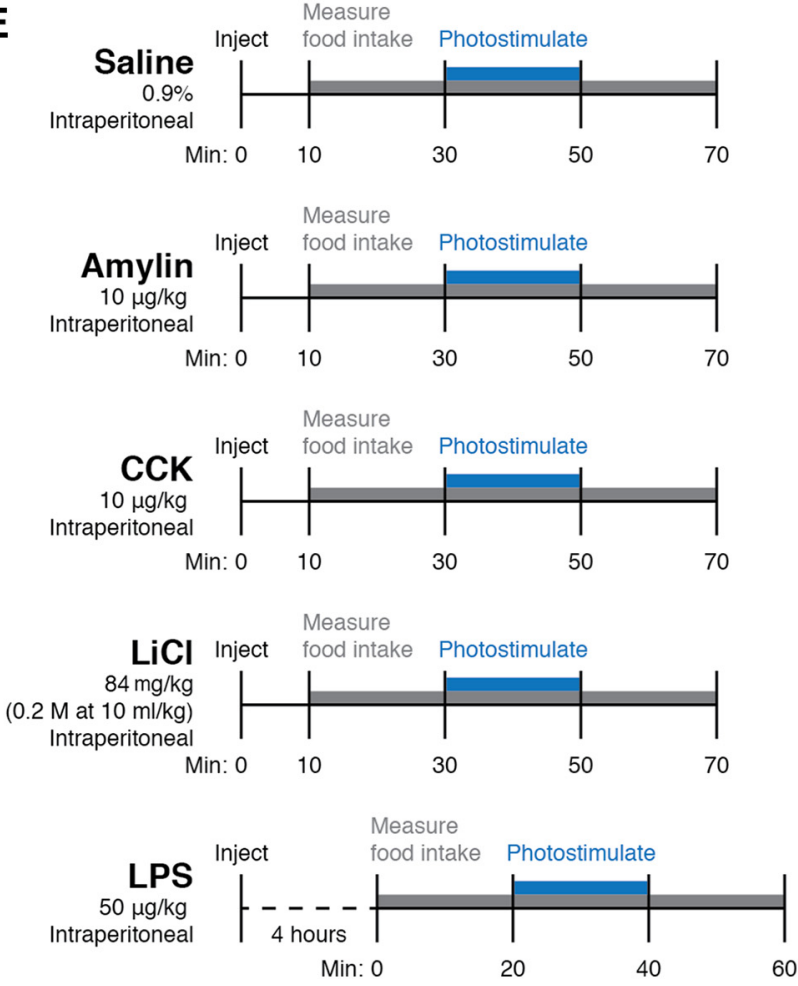

Figure 1. Optogenetic and pharmacological paradigms used to manipulate feeding behaviors. $A$, Diagram showing placement of a mono fiber-optic cannula above the arcuate nucleus and AAV constructs used to transduce AgRP neurons. Gray and black triangles represent loxP and lox2722 sites, respectively. $\boldsymbol{B}, \boldsymbol{C}$, Representative images showing unilateral expression of ChR2-mCherry $(\boldsymbol{B})$ or GFP $(\boldsymbol{C})$ in the arcuate nucleus. Dashed line shows approximate location of tips of fiber-optic implants. Scale bar, $250 \mu \mathrm{m}$. D, Photostimulation protocol. During the $20 \mathrm{~min}$ photostimulation period, $10 \mathrm{~ms}$ light pulses were delivered at $20 \mathrm{~Hz}$ for 1 s every 4 s. E, Injection timeline for food intake experiments. (amylin, CCK, $\mathrm{LiCl}$ ) and the saline control, injections were performed 10 min before recording of food intake ( $30 \mathrm{~min}$ before optogenetic stimulation; Fig. 1E). Because LPS does not suppress appetite immediately, but rather reduces appetite through initiation of an inflammatory response, LPS injections were performed $4 \mathrm{~h}$ before recording of food intake (Fig. $1 E$ ). All food intake trials were performed during the middle $4 \mathrm{~h}$ of the inactive period. The mice were allowed at least $24 \mathrm{~h}$ to recover from injection of amylin, CCK, and $\mathrm{LiCl}$ before subsequent trials began and at least $48 \mathrm{~h}$ to recover from injection of LPS to account for the additional recovery time due to the inflammatory response. A maximum of eight trials per compound were performed on each mouse.

For pharmacogenetic experiments, mice received an intraperitoneal injection of clozapine- $\mathrm{N}$-oxide (CNO; $0.5 \mathrm{mg} / \mathrm{kg}$, Sigma-Aldrich) $2 \mathrm{~h}$ before food intake measurements. The mice were allowed at least $48 \mathrm{~h}$ to recover between trials.

Histology. At the end of experimental procedures, mice were anesthetized with intraperitoneal injection of 2,2,2 tribromoethanol (SigmaAldrich, 48402) dissolved in Tert-amyl alcohol and sterile $0.9 \%$ saline. Mice were then transcardially perfused with cold $0.01 \mathrm{M}$ PBS, pH 7.4, followed by $4 \%$ paraformaldehyde in PBS. The brains were extracted, allowed to postfix overnight in $4 \%$ paraformaldehyde at $4^{\circ} \mathrm{C}$, and cryoprotected in $30 \%$ sucrose dissolved in PBS for an additional $24 \mathrm{~h}$ at $4^{\circ} \mathrm{C}$. Each brain was sectioned at $30 \mu \mathrm{m}$ on a microtome (Leica Microsystems) and collected in cold PBS.

For immunohistochemistry experiments, sections were washed three times in PBS with $0.2 \%$ Triton X-100 (PBST) for $10 \mathrm{~min}$ at room temperature. Sections were then incubated in a blocking solution composed of PBST with 3\% normal donkey serum (Jackson ImmunoResearch, 017-000-121) for $15 \mathrm{~min}$ at room temperature. For primary antibody exposure, sections were incubated in rabbit anti-Fos (1:1000; Cell Signaling Technology, 2250) in blocking solution overnight at $4^{\circ} \mathrm{C}$. After three 5 min washes in blocking solution, sections were incubated in AlexaFluor 488 donkey anti-rabbit (1:250; Jackson ImmunoResearch, 711-545-152) in block solution for $1 \mathrm{~h}$ at room temperature. Finally, sections were washed three times in PBS.

Brain sections were mounted in PBS onto SuperFrost Plus glass slides (VWR, 48311-703), coverslipped with Dapi Fluoromount-G (Southern Biotech, 0100-20), and stored in the dark at $4^{\circ} \mathrm{C}$ before microscopy and imaging. Slides were imaged using an Eclipse 80i epifluorescent microscope (Nikon), and images were captured using a RETIGNA 2000R digital camera. The resulting images were minimally processed using Photoshop CS5 (Adobe Systems) to enhance the brightness and contrast for optimal representation of the data. All digital images were processed in the same way between experimental conditions to avoid artificial manipulation between different datasets.

Quantification of colocalization of Fos and mCherry in the PBN was performed on adjacent sections from $\sim-4.90$ to $-5.50 \mathrm{~mm}$ from bregma (21 sections per mouse). All quantification analysis was performed by an investigator blinded to the identity of the conditions used to induce Fos.

Experimental design and statistical analysis. We used a between-subjects experimental design for all experiments except for those performed in Figure 3 , in which we used a within-subjects design (comparing ad libitum and food deprivation conditions within animals). All behavioral experiments included an $n \geq 5$ for each cohort of animals with at least five trials for each animal. All Fos expression experiments included an $n=5$ for each cohort of animals with a single trial for each animal. Data were analyzed using Prism 6.0 (GraphPad Software). Statistical tests included two-way ANOVA with repeated measures (Figs. 2, 3, 4D-F, 6B-G,I), two-way ANOVA without repeated measures (Fig. 5), and unpaired two-tailed $t$ test as described in the text.

\section{Results}

Optogenetic stimulation of AgRP neurons induces feeding following administration of noninflammatory anorexigenic compounds

To determine whether AgRP neuron stimulation is sufficient to induce feeding during various appetite-suppressing conditions, we unilaterally injected AAV carrying a Cre-dependent ChR2- 

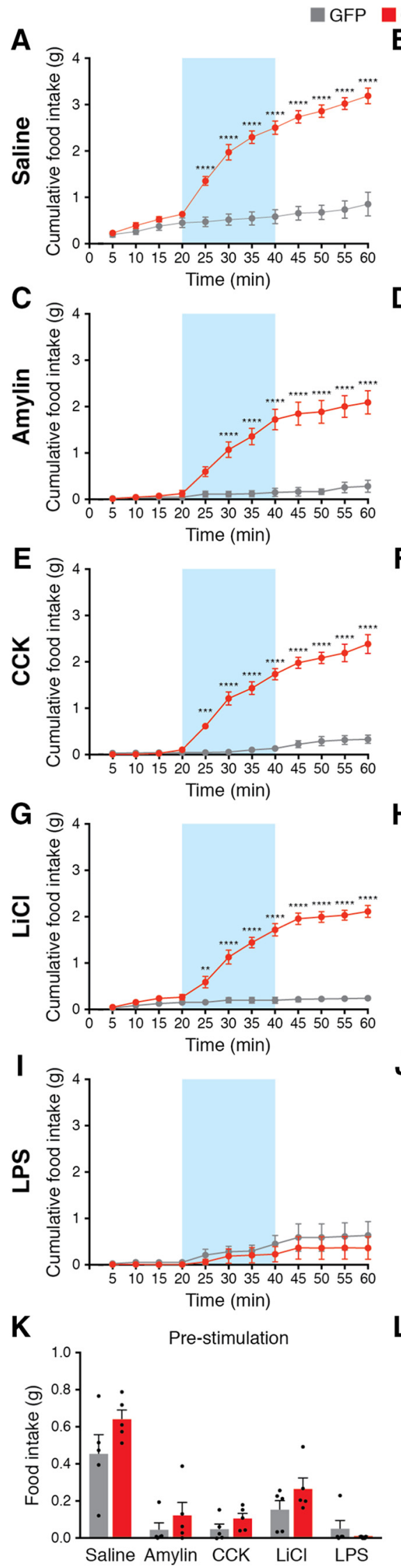

B
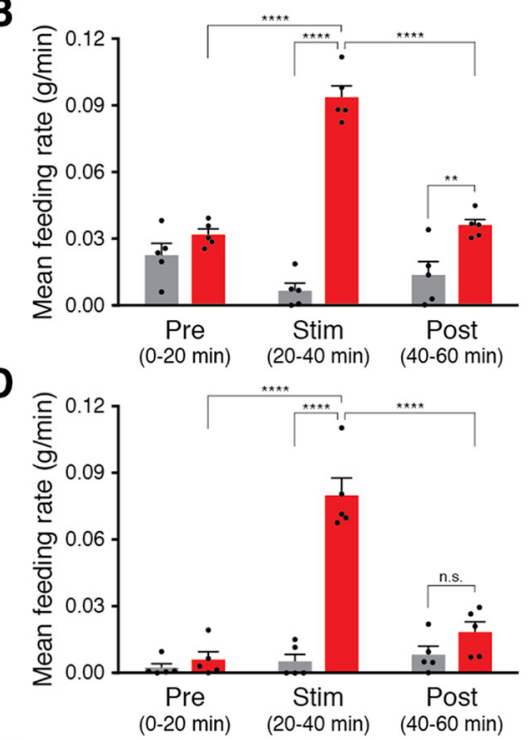

$\mathbf{F}$

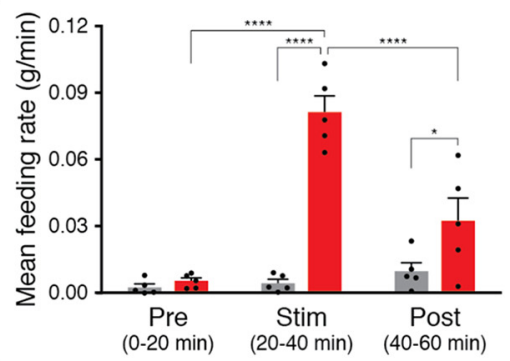

H

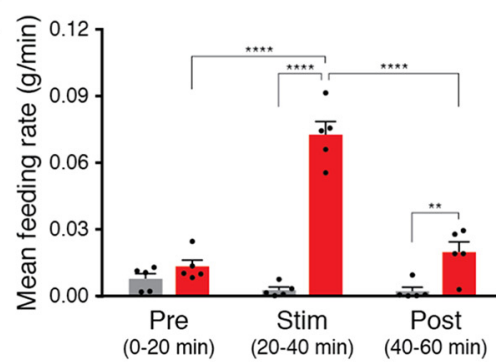

$\mathrm{J}$

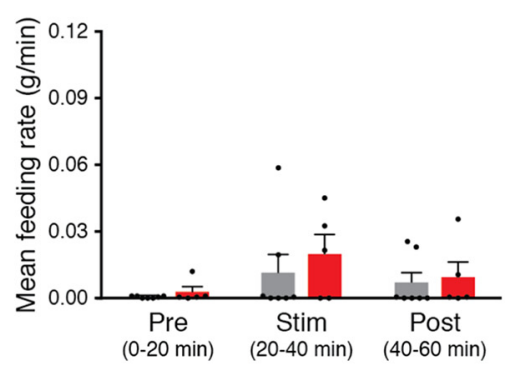

$\mathbf{L}$

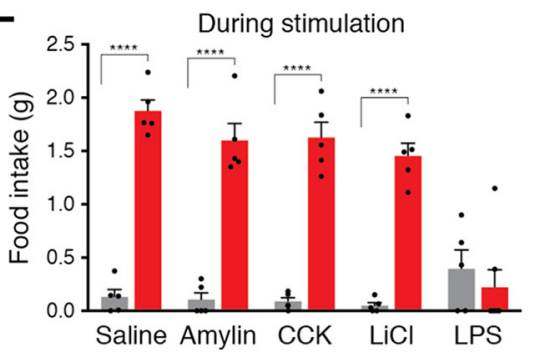

Figure 2. AgRP neuron stimulation is sufficient to increase feeding following administration of noninflammatory anorexigenic compounds. Stimulation of AgRP neurons rapidly and reversibly increased cumulative food intake (left) and mean feeding rate (right) following administration of saline $(\boldsymbol{A}, \boldsymbol{B})$, amylin $(\boldsymbol{C}, \boldsymbol{D}), \mathrm{CCK}(\boldsymbol{E}, \boldsymbol{F})$, and $\operatorname{LiCl}(\boldsymbol{G}, \boldsymbol{H})$, but not following administration of $\operatorname{LPS}(\boldsymbol{I}, \boldsymbol{J})$.
mCherry or GFP transgene into male $A g R P^{\text {Cre/+ }}$ knock-in mice (Fig. $1 A$ ). To suppress appetite, we injected mice intraperitoneally with amylin $(10 \mu \mathrm{g} / \mathrm{kg})$, CCK $(10 \mu \mathrm{g} / \mathrm{kg}), \mathrm{LiCl}(0.20 \mathrm{M} ; 84 \mathrm{mg} / \mathrm{kg})$, or LPS $(50 \mu \mathrm{g} / \mathrm{kg})$, all doses used in previous studies to maximally reduce food intake (Becskei et al., 2007; Rinaman and Dzmura, 2007; Carter et al., 2013; Liu et al., $2016)$, or a saline $(0.9 \%)$ control. Following administration of anorexigenic compounds, we measured food intake for $1 \mathrm{~h}$ and photostimulated mice during the middle $20 \mathrm{~min}$ of the recording session $(n=5$ mice per condition; Fig. $1 D, E)$. As expected following injection of saline, ChR2-mCherry-transduced animals had a significantly increased cumulative food intake (interaction of mice $\times$ time: $F_{(11,88)}=$ $89.8, p<0.0001$ ) and mean feeding rate (interaction of mice $\times$ time period: $F_{(2,16)}=$ $89.62, p<0.0001)$ compared with GFPtransduced animals (Fig. 2A,B), demonstrating the efficacy of optogenetic stimulation. ChR2-mCherry transduced animals also had a significantly increased cumulative food intake and mean feeding rate following injection of amylin (Fig. 2C,D), CCK (Fig. 2E,F), and LiCl (Fig. 2G,H), but these effects were completely absent following injection of LPS (Fig. 2I,J).

Importantly, all animals injected with anorexigenic compounds exhibited significantly reduced food intake in the 20 min before photostimulation of AgRP neurons compared with animals injected with saline, demonstrating the efficacy of these compounds in reducing food intake (interaction of compounds: $F_{(4,42)}=33.15$, $p<0.0001$; Fig. $2 K$ ). However, photostimulation eliminated the appetite-suppressing effects of amylin, CCK, and $\mathrm{LiCl}$, increasing feeding to levels similar to stimulated saline-injected animals (interaction of mice and compounds: $F_{(4,42)}=$ $21.13, p<0.0001$; Fig. $2 L)$. These photostimulation effects were absent in mice injected with LPS (Fig. 2L). Together, these data show that photostimulation of AgRP neurons can increase feeding following administration of amylin, CCK, and $\mathrm{LiCl}$, but not LPS.

Blue background represents the 20 min photostimulation period. All values represent the mean $\pm S E M$, black dots represent individual animals ( $n=5$ animals per group). $\boldsymbol{K}$, Total food consumed before stimulation of AgRP neurons across conditions. L, Total food consumed during stimulation of AgRP neurons across conditions. ${ }^{*} p<0.05,{ }^{* *} p<0.01,{ }^{* * *} p<$ $0.001,{ }^{* * * *} p<0.0001$, Bonferroni post hoc tests between groups; n.s., not significant. 
To gain additional insight into whether appetite-suppressing conditions can be overcome by endogenous hunger signals, we compared $1 \mathrm{~h}$ of food intake in animals injected with anorexigenic compounds in ad libitum fed and in $24 \mathrm{~h}$ food deprived conditions. All appetitesuppressing compounds reduced food intake in ad libitum fed animals compared with animals injected with saline $(n=5$ mice per condition; interaction of compound $\times$ feeding state: $F_{(4,20)}=9.29$, $p=0.0002$; Bonferroni's multiplecomparisons test across compound groups, $p<0.05$; Fig. 3), further demonstrating the efficacy of these compounds in reducing food intake. Twenty-four hour food deprivation caused a significant increase in food intake not only in animals injected with saline, but also in animals injected with amylin, CCK, and $\mathrm{LiCl}$ (Fig. 3), indicating that endogenous hunger signals are sufficient to overcome these appetite suppressors. Similar to AgRP neuron stimulation, $24 \mathrm{~h}$ food deprivation did not increase food intake in animals injected with LPS, suggesting that endogenous hunger signals cannot overcome inflammatory-based appetite suppression.

\section{Optogenetic stimulation of AgRP neurons ameliorates PBN CGRP-mediated appetite suppression and reduces Fos expression in PBN CGRP neurons}

Because stimulation of AgRP neurons overcame appetite suppression induced by amylin, $\mathrm{CCK}$, and $\mathrm{LiCl}$, all compounds that activate anorexigenic PBN CGRP neurons, we wondered whether AgRP neuron stimulation would also overcome appetite suppression induced by direct activation of PBN CGRP neurons. Activation of these neurons causes substantial reduction of food intake (Carter et al., 2013; Campos et al., 2016), yet it is unknown whether increased activity in orexigenic AgRP neurons can ameliorate this appetite suppression. Therefore, we activated CGRP neurons using the designer receptor $\mathrm{hM}_{3} \mathrm{Dq}$ and synthetic ligand clozapine- $N$-oxide $(\mathrm{CNO})$ and studied the effects of concurrently stimulating AgRP neurons. To stimulate both AgRP and PBN CGRP neurons, we crossed $\mathrm{AgRP} \mathrm{Cre} / \mathrm{Cre}^{\mathrm{mice}}$ with $\mathrm{Calca}^{\mathrm{Cre} /+}$ mice (Calca is the gene that encodes CGRP) to produce $\mathrm{AgRP} \mathrm{Cre/+}^{+}$; $\mathrm{Calca}^{\mathrm{Cre} /+}$ double knock-in animals. We transduced AgRP neurons with ChR2-mCherry or GFP, and transduced PBN CGRP neurons with $\mathrm{hM}_{3} \mathrm{Dq}$-mCherry or mCherry $(n=5$ mice per condition; Fig. $4 A-C$ ). As expected, injection of $\mathrm{CNO}$ in animals with $\mathrm{hM}_{3} \mathrm{Dq}$-mCherry-transduced CGRP neurons caused a significant reduction of both baseline food intake (interaction of mice $\times$ time: $F_{(33,176)}=54.6, p<0.0001$; Fig. $\left.4 D\right)$ and food intake in the $20 \mathrm{~min}$ period before AgRP neuron stimulation (interaction of CGRP-transduced mice: $F_{(1,16)}=33.18, p<$ 0.0001; Fig. 4E). Even during concurrent PBN CGRP neuronal activation, stimulation of AgRP neurons increased cumulative food intake (Fig. 4D), especially during the stimulation period (interaction of AgRP-transduced mice $\times$ CGRP-transduced mice: $F_{(1,16)}=5.553, p<0.0315$; Fig. $\left.4 F\right)$. Together, these data show that stimulation of AgRP neurons is sufficient to ameliorate PBN CGRP neuron-mediated appetite suppression, although feeding was not restored to the same amount as with AgRP neuron stimulation alone (Figs. $4 D, F$ ).

To determine whether stimulation of AgRP neurons decreases activity in PBN CGRP neurons, we repeated AgRP neuron pho- tostimulation experiments following administration of $\mathrm{CNO}$ in $\mathrm{hM}_{3}$ Dq-mCherry transduced animals and subsequently performed histological analysis of Fos expression, an indirect marker of neural activity. We perfused animals $90 \mathrm{~min}$ after the offset of photostimulation and collected brain sections throughout the ipsilateral parabrachial nucleus $(n=5$ mice per condition; Fig. $4 C$ ) to examine coincident expression of mCherry and Fos. Photostimulation of AgRP neurons significantly reduced the percentage of PBN CGRP neurons coexpressing Fos from $72.5 \pm$ $6.2 \%$ in GFP-transduced animals to $53.9 \pm 8.9 \%$ in ChR2mCherry-transduced animals (two-tailed unpaired $t$ test, $p=$ 0.005; Fig. 4G), demonstrating that AgRP neuron stimulation is sufficient to reduce neuronal activity in PBN CGRP neurons.

Injection of amylin, CCK, $\mathrm{LiCl}$, and LPS increases expression of Fos in PBN CGRP neurons (Carter et al., 2013). Because stimulation of AgRP neurons reduced Fos in chemogenetically activated PBN CGRP neurons (Fig. 4G), we hypothesized that stimulation of AgRP neurons would also reduce Fos in PBN CGRP neurons following administration of anorexigenic compounds. To test this hypothesis, we used $\mathrm{AgRP} \mathrm{Cre/+}^{+} \mathrm{Calca}^{\mathrm{Cre} /+}$ double knock-in animals, transducing AgRP neurons with ChR2-mCherry or TdTomato and transducing PBN CGRP neurons with mCherry $(n=5$ mice per condition; Fig. $5 A$ ). We repeated AgRP neuron photostimulation experiments following administration of anorexigenic compounds (Fig. 1E), perfusing animals 90 min after the offset of photostimulation. We then collected sections throughout the ipsilateral parabrachial nucleus (Fig. $5 A$ ) to examine coincident expression of mCherry and Fos. As expected, there was minimal Fos expression in mCherry-transduced CGRP neurons in animals injected with saline (Fig. 5B) and a high percentage of Fos expression in animals injected with anorexigenic compounds (Fig. $5 C-G)$. Photostimulation of AgRP neurons significantly reduced CGRP neuronal Fos expression in ChR2-mCherrytransduced animals compared with TdTomato-transduced animals (interaction of mice $\times$ compound: $F_{(4,40)}=9.257, p<$ 0.0001; Fig. 5G), demonstrating that AgRP neuron stimulation reduces neuronal activity in PBN CGRP neurons following administration of anorexigenic compounds.

\section{Optogenetic stimulation of AgRP neuron-to-PBN projections increases feeding following administration of anorexigenic compounds}

AgRP neurons send projections to the parabrachial nucleus ( $\mathrm{Wu}$ et al., 2009; Atasoy et al., 2012; Betley et al., 2013; Campos et al., 2016), and stimulation of these projections is sufficient to reduce expression of Fos in PBN CGRP neurons following adminis- 
A

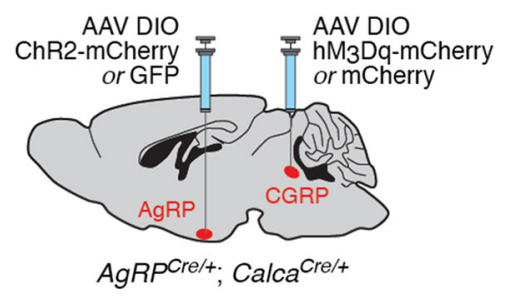

B

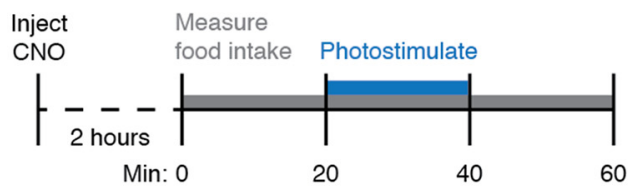

D

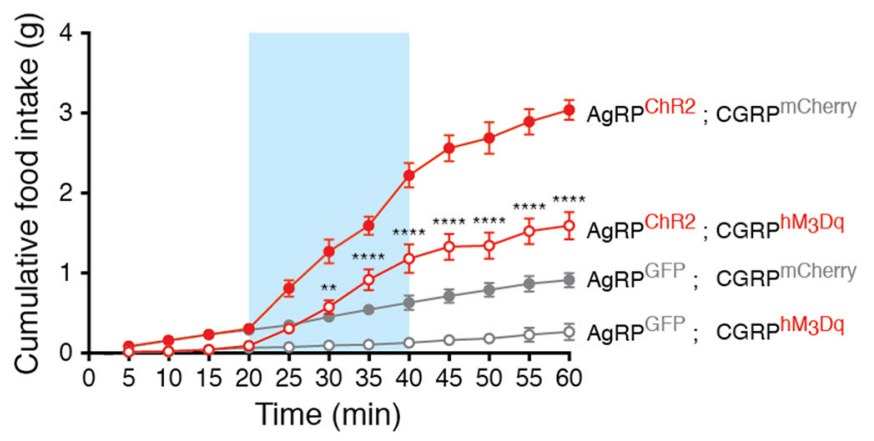

$\mathbf{E}$

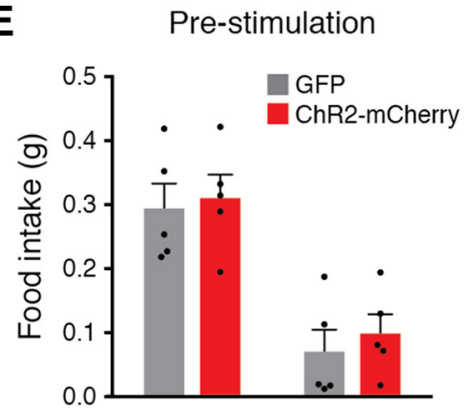

Transgene in PBN: mCherry hM3Dq-mCherry

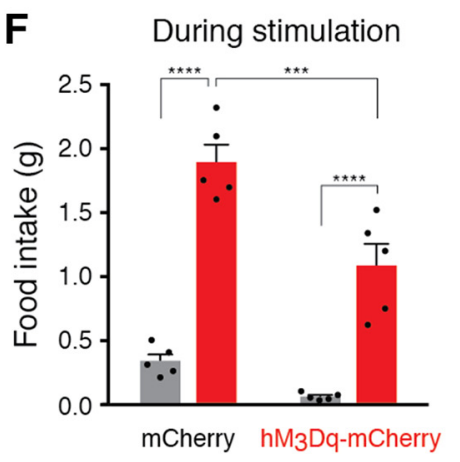

G
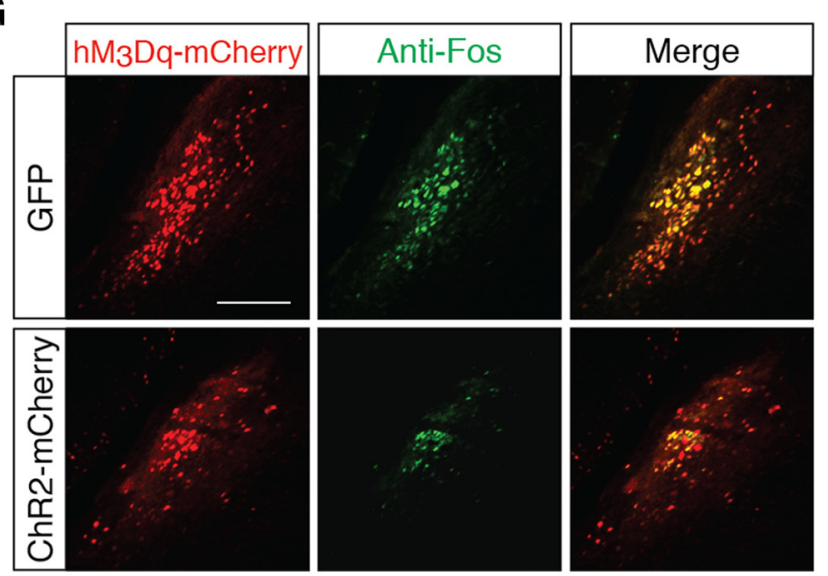

Figure 4. AgRP neuron stimulation is sufficient to increase feeding during chemogenetic stimulation of PBN CGRP neurons. $\boldsymbol{A}$, Viral injection strategy to transduce arcuate AgRP neurons and parabrachial CGRP neurons. $\boldsymbol{B}$, Timeline of CN0 administration and AgRP neuron photostimulation for each experimental trial. $C$, Top, Coronal diagram representing the location of PBN CGRP neurons; red square represents parabrachial region depicted in photomicrograph. Bottom, Representative image showing mCherry fluorescence in parabrachial CGRP neurons. scp, Superior cerebellar peduncle. Scale bar, $250 \mu \mathrm{m}$. D, Optogenetic stimulation of tration of the anorexigenic hormone exendin-4 (Campos et al., 2016). To determine whether selective stimulation of AgRP neuron-to-PBN projections is sufficient to induce feeding during various appetite-suppressing conditions, we bilaterally injected AAV carrying a Cre-dependent ChR2-mCherry or GFP transgene into male $A g R P^{C r e /+}$ knock-in mice and implanted bilateral fiber-optic cannulae above the lateral parabrachial nucleus $(n=5$ mice per condition; Fig. $6 A$ ). Similar to previous studies showing no effect of photostimulating AgRP-to-PBN projections in baseline conditions (Atasoy et al., 2012; Betley et al., 2013), we observed no effect of photostimulation on food intake between ChR2-mCherry- and GFPtransduced animals injected with saline (no interaction of mice $\times$ time: $F_{(11,44)}=$ 0.4574, $p=0.9192$; Fig. $6 B$ ). However, stimulation of AgRP-to-PBN projections was sufficient to increase food intake following injection of amylin, CCK, or $\mathrm{LiCl}$ (Fig. 6C-E). Similar to stimulation of AgRP neuron cell bodies, stimulation of AgRP-to-PBN projections did not increase food intake following injection of LPS (Fig. $6 F$ ). Importantly, stimulation of AgRP neuron-to-PBN projections increased food intake to levels similar to injection of saline (interaction of mice $\times$ compound: $F_{(4,16)}=3.027, p=0.049$; Fig. $\left.6 G\right)$, but did not increase food intake to levels similar to direct photostimulation of AgRP neuron soma (Fig. 2L). Therefore, stimulation of AgRP neuron-to-PBN projections overcomes the reduction of food intake following administration of amylin, CCK, and $\mathrm{LiCl}$, but does not induce food intake beyond baseline levels.

To determine whether stimulation of AgRP neuron projections to the $\mathrm{PBN}$ is sufficient to overcome appetite suppression induced by chemogenetic activation of PBN CGRP neurons, we used $\mathrm{AgRP} \mathrm{Cre/+}^{\text {; }}$

$\leftarrow$

AgRP neurons increases food intake during CGRP neuronmediated appetite suppression. All values represent the mean \pm SEM ( $n=5$ animals per group). Blue background represents the 20 min photostimulation period. ${ }^{* *} p<0.01$, ${ }^{* * * *} p<0.0001$, Bonferroni post hoc tests between AgRP GFP; $\mathrm{CGRP}^{\mathrm{hM} 3 \mathrm{Dq}}$ and $\mathrm{AgRP}{ }^{\mathrm{ChR} 2}$; $\mathrm{CGRP}^{\mathrm{hM} 3 \mathrm{Dq}}$ experimental groups at each time point. $\boldsymbol{E}$, Total food consumed before stimulation of AgRP neurons across conditions. $\boldsymbol{F}$, Total food consumed during stimulation of AgRP neurons across conditions. ${ }^{* *} p<$ $0.01,{ }^{* * *} p<0.0001$, Bonferroni post hoc tests between groups. G, Representative histological images showing coincident hM ${ }_{3}$ Dq-mCherry (red) and Fos (green) expression in CGRP neurons following injection of CNO in ChR2-mCherry- or GFPtransduced animals and photostimulation of AgRP neurons. Scale bar, $250 \mu \mathrm{m}$. 

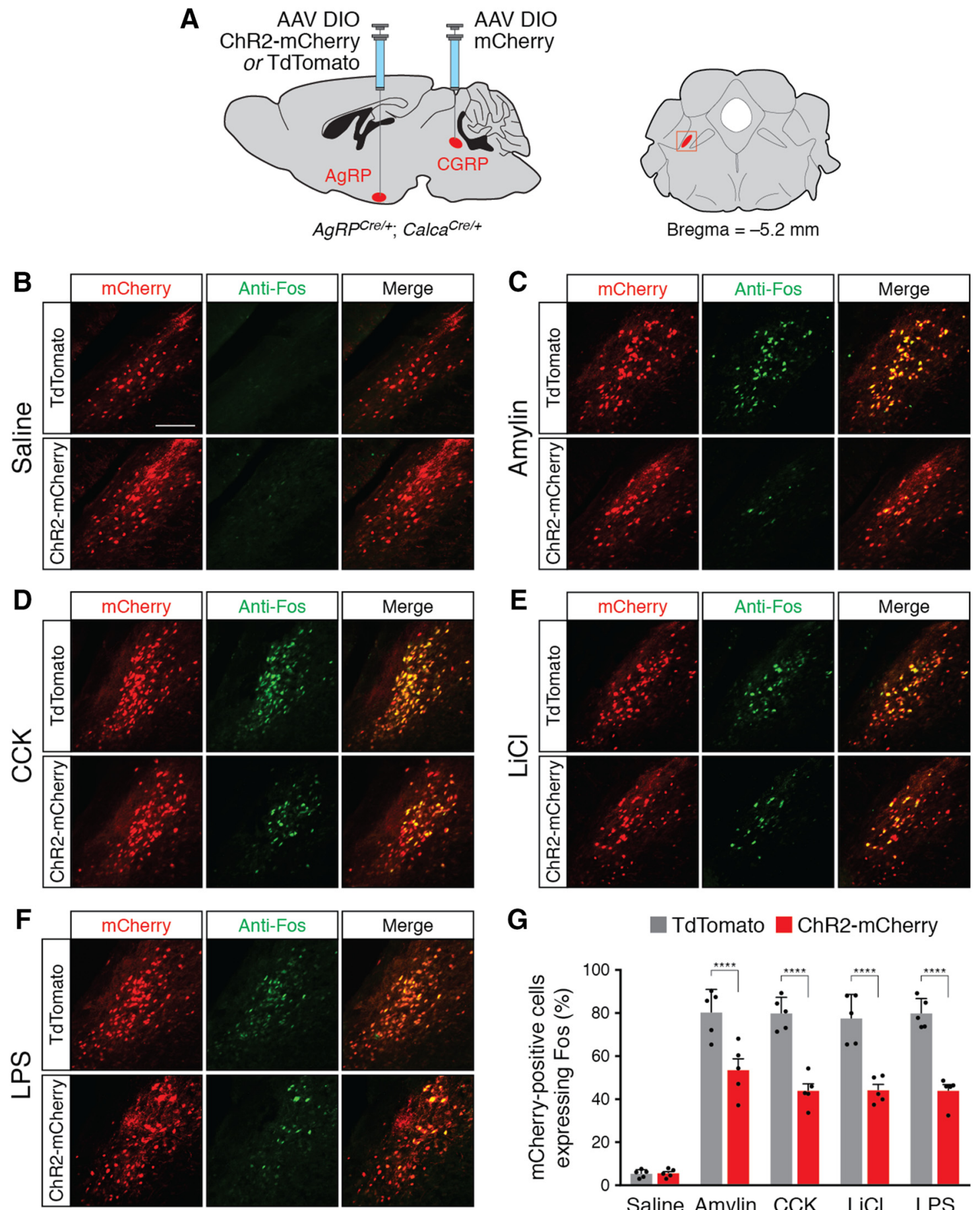

G

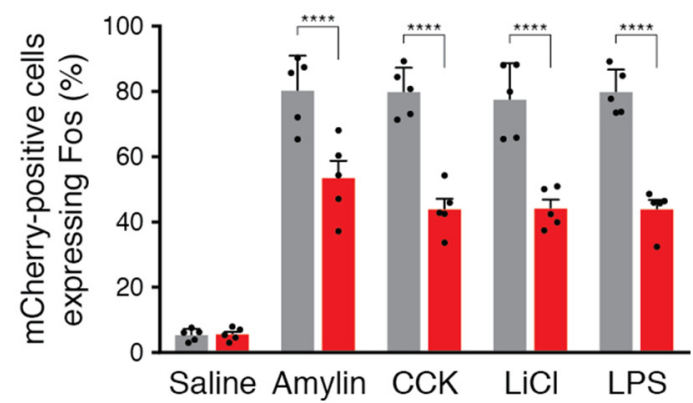

Figure 5. AgRP neuron stimulation reduces Fos expression in PBN CGRP neurons following administration of anorexigenic compounds. $A$, Injection strategy in $\mathrm{AgRP}^{\text {Cre/ }+}$; Calca ${ }^{\text {Cre/+ }}$ double knock-in mice. Right, Coronal diagram representing the location of CGRP neurons; red square represents parabrachial region depicted in photomicrographs. $\boldsymbol{B}-\boldsymbol{F}$, Representative histological images showing coincident mCherry (red) and Fos (green) expression in CGRP neurons following injection of saline ( $\boldsymbol{B})$, amylin (C), CCK (D), LiCl (E), and LPS (F), in ChR2-mCherry-or TdTomato-transduced animals, following photostimulation of AgRP neurons. Scale bar, $250 \mu \mathrm{m}$. G, Quantification of coexpression of mCherry and Fos in the parabrachial nucleus. All values represent the mean \pm SD, black dots represent individual animals ( $n=5$ animals per group). ${ }^{* * *} p<0.0001$, Bonferroni post hoc tests between TdTomato- and ChR2-mCherry-transduced animals.

$\mathrm{Calca}^{\mathrm{Cre} /+}$ double knock-in animals, unilaterally transducing AgRP neurons with ChR2-mCherry or GFP, transducing ipsilateral PBN CGRP neurons with $\mathrm{hM}_{3} \mathrm{Dq}$-mCherry, and implanting a unilateral fiber-optic cannula above the lateral PBN $(n=5$ mice per condition; Fig. $6 H$ ). Following administration of $\mathrm{CNO}$ (Fig. $4 B$ ), stimulation of AgRP fibers in the PBN significantly increased cumulative food intake (interaction of AgRP-transduced mice $\times$ time: $F_{(11,44)}=5.131, p<0.0001$; Fig. $\left.6 I\right)$. ChR2-mCherry- transduced animals consumed statistically more food $(0.18 \pm 0.078 \mathrm{~g})$ than GFP-transduced animals $(0.067 \pm 0.032 \mathrm{~g})$ during the 20 min stimulation period (two-tailed unpaired $t$ test, $p=0.018$ ), demonstrating that stimulation of AgRP neuron fibers in the PBN is sufficient to ameliorate PBN CGRP neuron-mediated appetite suppression.

To determine the effects of stimulation of AgRP neuron fibers in the PBN on activity in chemogenetically activated PBN CGRP 
A
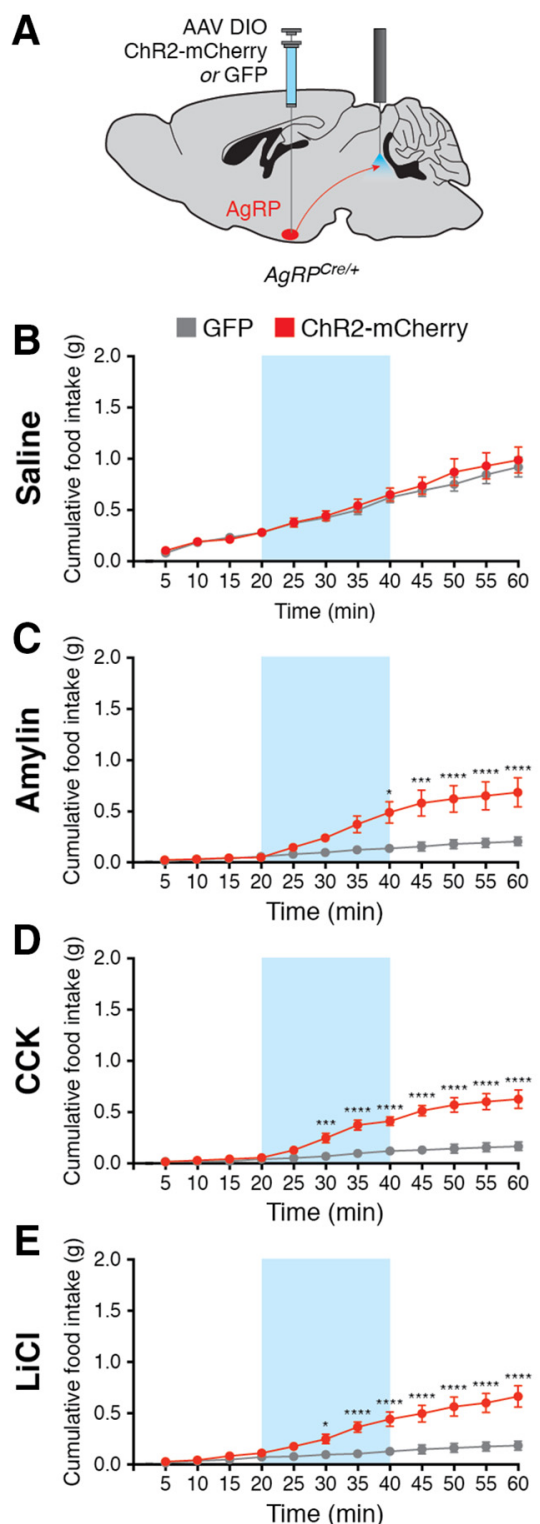

$\mathbf{F}$

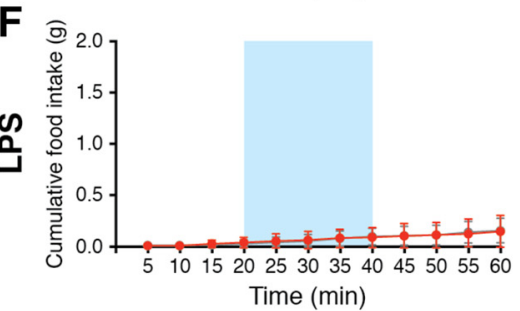

G

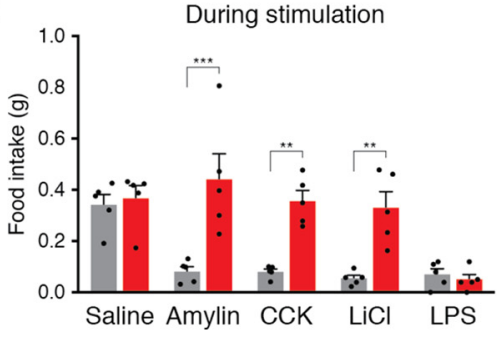

H
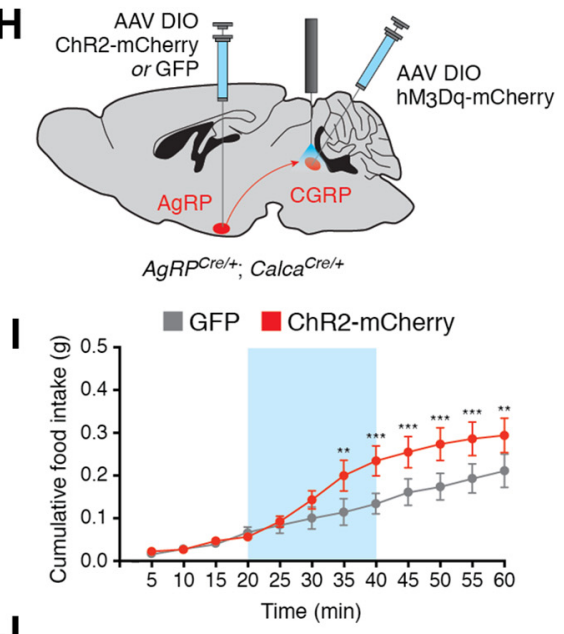

$\mathbf{J}$
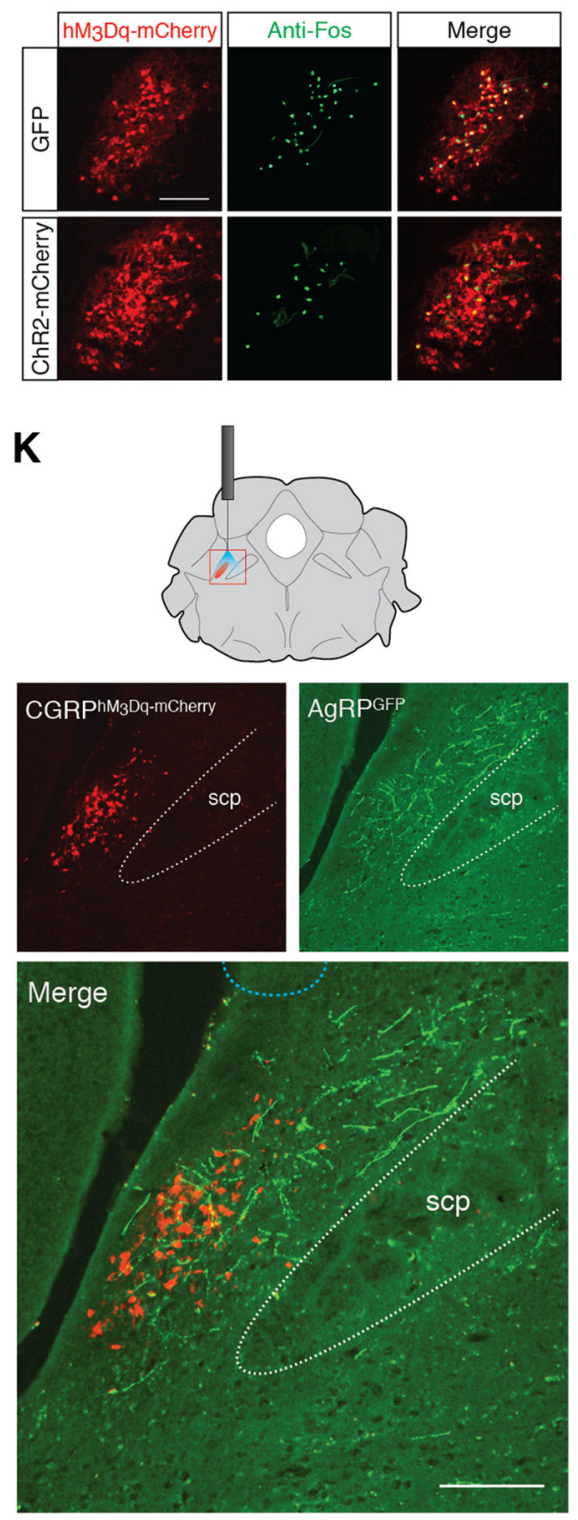

Figure 6. Stimulation of projections from AgRP neurons to parabrachial neurons increases feeding following administration of noninflammatory anorexigenic compounds. A, Injection strategy in $A g R P^{\text {Cre/+ }}$ mice for AgRP-to-PBN projection experiments. $B$, Stimulation of AgRP neuron projections has no effect on baseline food intake following administration of saline. Blue background represents the $20 \mathrm{~min}$ photostimulation period. $\mathbf{C}-\boldsymbol{F}$, Stimulation of AgRP neuron projections increases food intake following administration of amylin $(\boldsymbol{C}), C C K(\boldsymbol{D})$, and LiCl $(\boldsymbol{E})$, but not following administration of $\operatorname{LPS}(\boldsymbol{F}) .{ }^{*} p<0.05,{ }^{* *} p<0.01$,

neurons, we perfused animals 90 min after the offset of photostimulation and collected brain sections throughout the parabrachial nucleus $(n=5$ mice per condition) to examine coincident expression of mCherry and Fos. Photostimulation of AgRP neuron projections to the $\mathrm{PBN}$ significantly reduced the percentage of PBN CGRP neurons coexpressing Fos from $74.4 \pm 7.6 \%$ in GFP-transduced animals to $56.4 \pm 8.4 \%$ in ChR2-mCherrytransduced animals (two-tailed unpaired $t$ test, $p=0.007$; Fig. $6 \mathrm{~J}$ ), demonstrating that stimulation of AgRP neuron fibers in the PBN is sufficient to reduce neuronal activity in PBN CGRP neurons.

It is important to note that AgRP fibers did not project solely to the external lateral parabrachial area containing CGRP neurons, but indeed projected throughout the greater lateral $\mathrm{PBN}$ (Fig. $6 \mathrm{~K}$ ). Therefore, the effects of stimulating AgRP projections to the $\mathrm{PBN}$ may represent the inhibition of multiple cell types within the PBN.

\section{Discussion}

AgRP neurons are sufficient to increase food intake during noninflammatory conditions of appetite suppression

Together, these findings demonstrate that stimulation of AgRP neurons is sufficient to increase food intake following administration of various noninflammatory anorexigenic compounds. In addition to overcoming appetite suppression, AgRP neurons functionally inhibit anorexigenic

${ }^{* * *} p<0.001,{ }^{* * * *} p<0.0001$, Bonferroni post hoc tests between groups. $\mathbf{G}$, Total food consumed during stimulation of AgRP neurons across conditions. All values represent the mean \pm SEM, black dots represent individual animals $(n=5$ animals per group). ${ }^{* *} p<0.01,{ }^{* * *} p<0.001$, Bonferroni post hoc tests between groups. $\boldsymbol{H}$, Injection strategy in $\mathrm{AgRP}^{\mathrm{Cre} /+}$; $\mathrm{Calca}^{\text {Cre/+ }}$ double knock-in mice for AgRP-to-PBN projection experiments with $\mathrm{hM}_{3} \mathrm{Dq}$-mediated stimulation of CGRP neurons. I, Stimulation of AgRP neuron projections increases food intake following injection of $\mathrm{CNO}$. ${ }^{* *} p<0.01$, ${ }^{* * *} p<0.001$, Bonferroni post hoc tests between groups. $J$, Representative histological images showing coincident hM3Dq-mCherry (red) and Fos (green) expression in CGRP neurons following injection of CNO in ChR2-mCherry- or GFPtransduced animals and photostimulation of AgRP neurons. Scale bar, $250 \mu \mathrm{m} . \boldsymbol{K}$, AgRP neuron projections throughout the lateral parabrachial nucleus. Top, Coronal diagram representing the location of GRRP neurons; red square represents parabrachial region depicted in photomicrographs. Bottom, Representative images showing $\mathrm{hM}_{3} \mathrm{Dq}$-mCherry transduced CGRP neurons and GFP-transduced AgRP fiber projections in the lateral parabrachial nucleus. scp, Superior cerebellar peduncle. Light blue dashed line at top of bottom image shows approximate location of tips of fiber-optic implants. Scale bar, $250 \mu \mathrm{m}$. 


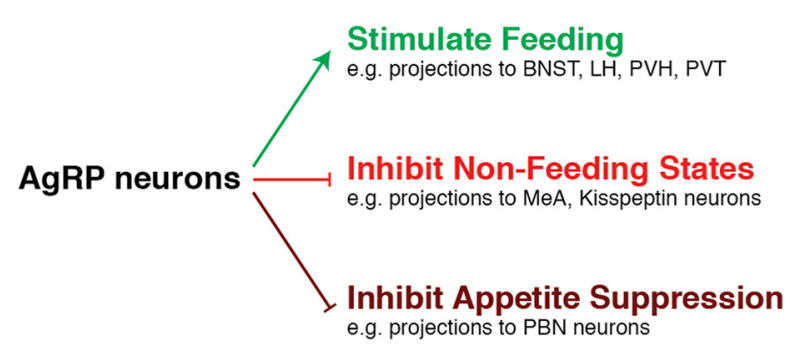

e.g. projections to PBN neurons

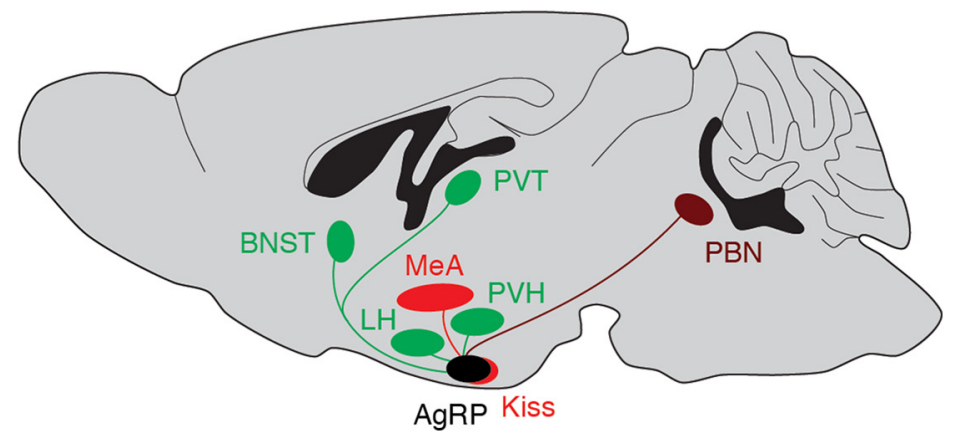

Figure 7. Model of functional anatomy of AgRP neuron projections. AgRP neurons increase food intake by projecting to downstream populations (green connections) that initiate feeding including the bed nucleus of the stria terminalis (BNST), lateral hypothalamus (LH), paraventricular hypothalamic nucleus (PVH), and paraventricular thalamic nucleus (PVT). AgRP neurons also inhibit other nonfeeding behavioral/physiological states by projecting to downstream regions (red connections) such as the MeA to inhibit fear and aggression or arcuate kisspeptin neurons (Kiss) to inhibit reproduction. Our results demonstrate that AgRP neurons disengage noninflammatory appetite-suppressing states by projecting to the PBN (dark red connections).

CGRP neurons in the PBN. Furthermore, stimulation of projections from AgRP neurons to the PBN is sufficient to overcome appetite suppression following amylin, CCK, or LiCl administration, increasing food intake to baseline values. Therefore, we conclude that AgRP neurons not only actively engage with downstream circuits that cause food-seeking behavior, but also actively inhibit parabrachial neurons that suppress appetite.

The ability of AgRP neurons to overcome hormonal satiety signals and transient gastrointestinal malaise suggests that homeostatic feeding signals can continue to stimulate appetite even during anorexigenic conditions. Consistent with this hypothesis, AgRP neurons decrease activity immediately upon sensory exposure to food (Betley et al., 2015; Chen et al., 2015; MandelblatCerf et al., 2015), although activity in these neurons is still increased relative to a sated state (Mandelblat-Cerf et al., 2015). This suppression of activity in AgRP neurons may allow anorexigenic signals to exert increased effects on suppressing food intake during a meal. Because AgRP neurons respond not only to hormonal signals but also to top-down neuronal signaling (Krashes et al., 2014; Garfield et al., 2016), cortical and higher order brain regions likely counteract anorexigenic peripheral signals to increase food intake depending on food palatability and caloric need.

\section{AgRP neurons are not sufficient to increase food intake during conditions of inflammatory-based appetite suppression}

A major question raised by this study is how AgRP neuron stimulation is sufficient to increase food intake following administration of amylin, CCK, and $\mathrm{LiCl}$, but not administration of LPS. This result is consistent with a recent finding that LPS completely blocks food intake following chemogenetic stimulation of AgRP neurons (Liu et al., 2016). In our study, it is possible that the distinct timing of LPS administration (Fig. 1E) contributed to its differential effects, but not likely, as we chose stimulation parameters based on when each compound exerted a maximal anorexigenic effect. It is also possible that the different doses of compounds used caused differential effects, but again not likely, as our doses all suppressed appetite before AgRP neuron stimulation (Fig. $2 K$ ), all induced expression of Fos in downstream PBN CGRP neurons (Fig. 5G), and are all consistent with moderate doses used in many previous studies to reduce food intake (Becskei et al., 2007; Rinaman and Dzmura, 2007; Carter et al., 2013; Liu et al., 2016). Instead, because stimulation of AgRP neuron-to-PBN fibers overcame appetite suppression following amylin, $\mathrm{CCK}$, and $\mathrm{LiCl}$ administration but not LPS, we propose that LPS-mediated anorexia represents a form of appetite suppression that engages neurons in several brain regions in addition to those in the PBN. Indeed, previous studies have demonstrated robust Fos expression and microglial activation throughout the brain following LPS administration, indicating that LPS probably causes anorexigenic effects by engaging multiple brain systems (Elmquist et al., 1996; Konsman et al., 1999; Liu et al., 2016; Fernández-Calle et al., 2017). Therefore, stimulation of AgRP neurons is sufficient to reduce LPS-induced Fos expression in PBN CGRP neurons (Fig. 5) but insufficient to overcome LPSinduced appetite suppression. Interestingly, direct inhibition of PBN CGRP neurons using chemogenetics is sufficient to mildly blunt the anorexigenic effects of LPS (Carter et al., 2013), suggesting that stimulation of AgRP neurons does not fully inhibit PBN CGRP neurons to the same degree.

\section{Functional connectivity between AgRP neurons, PBN CGRP neurons, and other downstream brain regions}

Another major question raised by this study is the nature of the connectivity between AgRP and PBN CGRP neurons. Although stimulation of AgRP neurons decreased activity (as measured by Fos expression) in PBN CGRP neurons (Fig. 5) and stimulation of AgRP neuron fibers to the PBN overcame appetite suppression (Fig. 6), we note that this connectivity does not necessitate a monosynaptic connection. Campos et al. (2016) showed that AgRP fibers are located among PBN CGRP neurons, and that a Cre-dependent modified rabies retrograde reporter from PBN CGRP neurons was detected in a fraction of AgRP neurons. However, we observed dense AgRP fibers throughout the lateral PBN in addition to opposing CGRP neurons (Fig. $6 K$ ), consistent with expression patterns described in previous studies (Atasoy et al., 2012; Betley et al., 2013). It is therefore possible that AgRP neurons inhibit CGRP neurons indirectly through other PBN circuits. Because the PBN is a heterogeneous region containing many genetically and functionally distinct cell types, a survey of the connectivity between AgRP neurons and individual PBN neurons is an open area for future investigation.

Interestingly, AgRP neuron stimulation only partially attenuated Fos activation in PBN CGRP neurons $(\sim 20-50 \%$ reduction across conditions; Figs. 4G, 5, $6 \mathrm{~J}$ ), yet stimulation of AgRP neurons or stimulation of AgRP neural projections to the PBN overcame multiple appetite-suppressing conditions. These results could indicate the involvement of other cell types in the lateral $\mathrm{PBN}$ that also overcome appetite suppression, but could also be due to Fos protein dynamics. Although Fos is routinely used as an indirect measure of neuronal activity, its expression is not tem- 
porally precise, and immunohistochemical detection of Fos is not quantitatively representative of total Fos protein within a cell. Therefore, we conclude that a $20-50 \%$ reduction of Fos in PBN CGRP neurons following 20 min AgRP neuron stimulation indicates a reduction of activity in these neurons, but does not quantitatively reveal the degree of this reduction during the $20 \mathrm{~min}$ AgRP neuron stimulation period.

Recent studies have identified noncanonical functions for efferent AgRP neuron projections that provide context for the role of AgRP-to-PBN connections. AgRP neurons stimulate food intake via projections to the bed nucleus of the stria terminalis, the lateral hypothalamus, the paraventricular hypothalamic nucleus, and the paraventricular thalamic nucleus (Betley et al., 2013). Additionally, AgRP neurons directly inhibit brain systems that mediate other behavioral states that competitively decrease feeding and food-seeking behavior. For example, AgRP neurons directly inhibit neurons in the medial amygdala (MeA) to decrease territorial aggression and contextual fear, and kisspeptin (Kiss) neurons in the hypothalamus to decrease fertility, presumably linking nutritional state and resource expenditure (Padilla et al., 2016, 2017). Additionally, AgRP neuron activation has been shown to decrease water-seeking and social behaviors (Burnett et al., 2016). Thus, activation of AgRP neurons stimulates foodseeking behavior while actively suppressing behaviors that competitively decrease food intake. Livneh et al. (2017) recently demonstrated that chemogenetic stimulation of AgRP neurons can bypass the effects of satiety signals to restore hunger-like patterns of activity in insular cortex. Our results complement these findings, demonstrating that projections from AgRP neurons to the PBN can overcome various forms of appetite suppression to increase feeding behavior (Fig. 7).

\section{References}

Aponte Y, Atasoy D, Sternson SM (2011) AGRP neurons are sufficient to orchestrate feeding behavior rapidly and without training. Nat Neurosci 14:351-355. CrossRef Medline

Atasoy D, Betley JN, Su HH, Sternson SM (2012) Deconstruction of a neural circuit for hunger. Nature 488:172-177. CrossRef Medline

Becskei C, Grabler V, Edwards GL, Riediger T, Lutz TA (2007) Lesion of the lateral parabrachial nucleus attenuates the anorectic effect of peripheral amylin and CCK. Brain Res 1162:76-84. CrossRef Medline

Betley JN, Cao ZF, Ritola KD, Sternson SM (2013) Parallel, redundant circuit organization for homeostatic control of feeding behavior. Cell 155: 1337-1350. CrossRef Medline

Betley JN, Xu S, Cao ZF, Gong R, Magnus CJ, Yu Y, Sternson SM (2015) Neurons for hunger and thirst transmit a negative-valence teaching signal. Nature 521:180-185. CrossRef Medline

Burnett CJ, Li C, Webber E, Tsaousidou E, Xue SY, Brüning JC, Krashes MJ (2016) Hunger-driven motivational state competition. Neuron 92:187201. CrossRef Medline

Campos CA, Bowen AJ, Schwartz MW, Palmiter RD (2016) Parabrachial CGRP neurons control meal termination. Cell Metab 23:811-820. CrossRef Medline

Carter ME, Soden ME, Zweifel LS, Palmiter RD (2013) Genetic identification of a neural circuit that suppresses appetite. Nature 503:111-114. CrossRef Medline

Carter ME, Han S, Palmiter RD (2015) Parabrachial calcitonin gene-related peptide neurons mediate conditioned taste aversion. J Neurosci 35:45824586. CrossRef Medline

Chen Y, Lin YC, Kuo TW, Knight ZA (2015) Sensory detection of food rapidly modulates arcuate feeding circuits. Cell 160:829-841. CrossRef Medline

Elmquist JK, Scammell TE, Jacobson CD, Saper CB (1996) Distribution of
Fos-like immunoreactivity in the rat brain following intravenous lipopolysaccharide administration. J Comp Neurol 371:85-103. CrossRef Medline

Fernández-Calle R, Vicente-Rodríguez M, Gramage E, Pita J, Pérez-Garcia C, Ferrer-Alcón M, Uribarri M, Ramos MP, Herradón G (2017) Pleiotrophin regulates microglia-mediated neuroinflammation. J Neuroinflammation 14:46. CrossRef Medline

Garfield AS, Shah BP, Burgess CR, Li MM, Li C, Steger JS, Madara JC, Campbell JN, Kroeger D, Scammell TE, Tannous BA, Myers MG Jr, Andermann ML, Krashes MJ, Lowell BB (2016) Dynamic GABAergic afferent modulation of AgRP neurons. Nat Neurosci 19:1628-1635. CrossRef Medline

Ilnytska O, Argyropoulos G (2008) The role of the agouti-related protein in energy balance regulation. Cell Mol Life Sci 65:2721-2731. CrossRef Medline

Konsman JP, Kelley K, Dantzer R (1999) Temporal and spatial relationships between lipopolysaccharide-induced expression of Fos, interleukin-1beta and inducible nitric oxide synthase in rat brain. Neuroscience 89:535548. CrossRef Medline

Krashes MJ, Koda S, Ye C, Rogan SC, Adams AC, Cusher DS, Maratos-Flier E, Roth BL, Lowell BB (2011) Rapid, reversible activation of AgRP neurons drives feeding behavior in mice. J Clin Invest 121:1424-1428. CrossRef Medline

Krashes MJ, Shah BP, Madara JC, Olson DP, Strochlic DE, Garfield AS, Vong L, Pei H, Watabe-Uchida M, Uchida N, Liberles SD, Lowell BB (2014) An excitatory paraventricular nucleus to AgRP neuron circuit that drives hunger. Nature 507:238-242. CrossRef Medline

Liu Y, Huang Y, Liu T, Wu H, Cui H, Gautron L (2016) Lipopolysacharide rapidly and completely suppresses AgRP neuron-mediated food intake in male mice. Endocrinology 157:2380-2392. CrossRef Medline

Livneh Y, Ramesh RN, Burgess CR, Levandowski KM, Madara JC, Fenselau H, Goldey GJ, Diaz VE, Jikomes N, Resch JM, Lowell BB, Andermann ML (2017) Homeostatic circuits selectively gate food cue responses in insular cortex. Nature 546:611-616. CrossRef Medline

Luquet S, Perez FA, Hnasko TS, Palmiter RD (2005) NPY/AgRP neurons are essential for feeding in adult mice but can be ablated in neonates. Science 310:683-685. CrossRef Medline

Mandelblat-Cerf Y, Ramesh RN, Burgess CR, Patella P, Yang Z, Lowell BB, Andermann ML (2015) Arcuate hypothalamic AgRP and putative POMC neurons show opposite changes in spiking across multiple timescales. eLife 4:e07122. CrossRef Medline

Padilla SL, Qiu J, Soden ME, Sanz E, Nestor CC, Barker FD, Quintana A, Zweifel LS, Rønnekleiv OK, Kelly MJ, Palmiter RD (2016) Agoutirelated peptide neural circuits mediate adaptive behaviors in the starved state. Nat Neurosci 19:734-741. CrossRef Medline

Padilla SL, Qiu J, Nestor CC, Zhang C, Smith AW, Whiddon BB, Rønnekleiv OK, Kelly MJ, Palmiter RD (2017) AgRP to Kiss1 neuron signaling links nutritional state and fertility. Proc Natl Acad Sci U S A 114:2413-2418. CrossRef Medline

Rinaman L, Dzmura V (2007) Experimental dissociation of neural circuits underlying conditioned avoidance and hypophagic responses to lithium chloride. Am J Physiol Regul Integr Comp Physiol 293:R1495-R1503. CrossRef Medline

Sternson SM (2013) Hypothalamic survival circuits: blueprints for purposive behaviors. Neuron 77:810-824. CrossRef Medline

Sternson SM, Eiselt AK (2017) Three pillars for the neural control of appetite. Annu Rev Physiol 79:401-423. CrossRef Medline

Takahashi KA, Cone RD (2005) Fasting induces a large, leptin-dependent increase in the intrinsic action potential frequency of orexigenic arcuate nucleus neuropeptide Y/Agouti-related protein neurons. Endocrinology 146:1043-1047. CrossRef Medline

Tong Q, Ye CP, Jones JE, Elmquist JK, Lowell BB (2008) Synaptic release of GABA by AgRP neurons is required for normal regulation of energy balance. Nat Neurosci 11:998-1000. CrossRef Medline

Wu Q, Boyle MP, Palmiter RD (2009) Loss of GABAergic signaling by AgRP neurons to the parabrachial nucleus leads to starvation. Cell 137:12251234. CrossRef Medline 